\title{
Metal complexes with two different hydrogen-bond donor ligands as anion hosts $\dagger$
}

\author{
Sonia Nieto, ${ }^{a}$ Julio Pérez, ${ }^{* a}$ Lucía Riera, ${ }^{* a}$ Víctor Riera ${ }^{a}$ and Daniel Miguel ${ }^{b}$ \\ Received (in Cambridge, UK) 5th January 2009, Accepted 25th March 2009 \\ First published as an Advance Article on the web 24th April 2009 \\ DOI: $10.1039 / \mathbf{b 8 2 3 4 6 0 d}$
}

The replacement of one pyrazole ligand by 2 -aminopyridine in previously known rhenium tricarbonyl pyrazole complexes leads to more selective anion hosts.

Metal complexes containing ligands functionalized with hydrogen-bond donor groups can be used as anion hosts, and their synthesis is often easier than those of purely organic hosts. ${ }^{1}$ We have reported hosts of this type based on cationic complexes of the $f a c-\left\{\operatorname{Re}(\mathrm{CO})_{3}\right\}$ fragment and three azole ligands, as salts of $\mathrm{BAr}_{4}^{\prime}\left(\mathrm{Ar}^{\prime}=3,5\right.$-bis(trifluoromethyl)phenyl), more innocent and inert than the more widely used anions $\mathrm{PF}_{6}{ }^{-}$or $\mathrm{BF}_{4}{ }^{-2,3}$ The choice of the inert metal fragment aimed to provide hosts stable against substitution of the neutral ligands by the anionic guests, and the presence of CO ligands makes IR spectroscopy a useful tool to detect such a substitution, ligand deprotonation, etc. ${ }^{4}$ It occurred to us that their modular synthesis, ${ }^{2}$ from a suitable metal precursor and the free azoles, could allow the preparation of hosts comprising more than one type of functionalized ligand. Such a modification could afford a selectivity higher than that of the more symmetric hosts. To test this idea we chose to modify the fac- $\left[\operatorname{Re}(\mathrm{CO})_{3}(\mathrm{Hdmpz})_{3}\right] \mathrm{BAr}^{\prime}{ }_{4}(\mathrm{Hdmpz}=3,5$-dimethylpyrazole $)$ compounds by replacing one of the pyrazole ligands by an aminopyridine, a ligand employed by Steed et. al. in ruthenium-based hosts. ${ }^{5}$

The reaction of $\left[\operatorname{ReBr}(\mathrm{CO})_{3}(\mathrm{Hdmpz})_{2}\right]$ (prepared by thermal reaction of $\left[\operatorname{ReBr}(\mathrm{CO})_{5}\right]$ with two equivalents of $\mathrm{Hdmpz}$ ) with AgOTf (to replace bromide by triflate), followed by addition of the salt $\mathrm{NaBAr}_{4}{ }_{4}$ and either 2-aminopyridine (2-ampy) or 3-aminopyridine (3-ampy) afforded the new compounds $f a c-\left[\operatorname{Re}(\mathrm{CO})_{3}(\mathrm{Hdmpz})_{2}(2-\mathrm{ampy})\right] \mathrm{BAr}^{\prime}{ }_{4}\left(\mathbf{1} \cdot \mathrm{BAr}^{\prime}{ }_{4}\right) \ddagger$ and $f a c-\left[\operatorname{Re}(\mathrm{CO})_{3}(\mathrm{Hdmpz})_{2}(3-\mathrm{ampy})\right] \mathrm{BAr}^{\prime}{ }_{4} \quad\left(\mathbf{2} \cdot \mathrm{BAr}^{\prime}{ }_{4}\right), \S$ see Scheme 1 . Compounds $\mathbf{1} \cdot \mathrm{BAr}^{\prime}{ }_{4}$ and $\mathbf{2} \cdot \mathrm{BAr}^{\prime}{ }_{4}$ were characterized by IR, NMR and microanalysis $(\mathrm{C}, \mathrm{H}, \mathrm{N})$. The IR spectra were typical of cationic complexes of the $f a c-\left\{\operatorname{Re}(\mathrm{CO})_{3}\right\}$ fragment, with $\nu_{\mathrm{CO}}$ values similar to those of the tris(pyrazole) complexes mentioned above. ${ }^{2}$ The ${ }^{1} \mathrm{H}$ NMR spectra featured different signals for the two methyl groups in the 3 and 5 positions of the pyrazole ligands, indicating that these ligands

${ }^{a}$ Departamento de Química Orgánica e Inorgánica-IUQOEM, Facultad de Química, Universidad de Oviedo-CSIC, 33006, Oviedo, Spain.E-mail: rieralucia.uo@uniovi.es,japm@uniovi.es; Fax: 349851 03446; Tel: 34985103465

${ }^{b}$ Departamento de Química Inorgánica, Facultad de Ciencias, Universidad de Valladolid, 47005, Valladolid, Spain

$\dagger$ Electronic supplementary information (ESI) available: X-Ray crystallographic data for compounds $1 \cdot \mathrm{ClO}_{4}, \mathbf{2} \cdot \mathrm{BAr}_{4}^{\prime}, \mathbf{2} \cdot \mathrm{ClO}_{4}, \mathbf{2} \cdot \mathrm{Br}$ and $2 \cdot \mathrm{NO}_{3} \cdot{ }^{1} \mathrm{H}$ NMR titration profiles and experimental details. CCDC 715278-715282. For ESI and crystallographic data in CIF or other electronic format see DOI: 10.1039/b823460d

do not experience a fast dissociation-recoordination process, which would lead to the observation of a single methyl signal. The presence of only one set of pyrazole resonances in ${ }^{1} \mathrm{H}$ and ${ }^{13} \mathrm{C}$ NMR, and only two carbonyl signals in ${ }^{13} \mathrm{C}$ NMR for the three $\mathrm{CO}$ ligands, indicate the presence of a molecular mirror plane. Attempts to grow single crystals of $\mathbf{1} \cdot \mathrm{BAr}_{4}{ }_{4}$ failed, but anion exchange with $\left[\mathrm{Bu}_{4} \mathrm{~N}\right]\left[\mathrm{ClO}_{4}\right]$ afforded single crystals of 1. $\mathrm{ClO}_{4}$, which were used for the structural determination. ${ }^{6}$ The results confirmed the formulation inferred from the spectroscopy data summarized above (see Fig. 1(a)). The 2-ampy ligand binds $\mathrm{Re}$ through the $\mathrm{NH}_{2}$ group, a coordination mode less frequently found in transition metal complexes than binding through the pyridine nitrogen. ${ }^{7}$ This feature is attributed to the presence of an intramolecular hydrogen bond between the $\mathrm{N}-\mathrm{H}$ group of one of the pyrazole ligands and the pyridine nitrogen, characterized by $\mathrm{N} 4 \cdots \mathrm{N} 6=2.893(7) \AA$ and $\mathrm{N} 4-\mathrm{H} \cdots \mathrm{N} 6=162.3(6)^{\circ}$. The $\mathrm{ClO}_{4}{ }^{-}$anion forms weak hydrogen bonds with $\mathrm{N}-\mathrm{H}$ groups of pyrazole and 2-ampy ligands. Fig. 1(a) shows, as dotted lines, the hydrogen bonds of the perchlorate anion with one cationic host (for a more complete view, showing also H-bonds with a second cation or the structural packing, see ESI $\dagger$ ).

When an equimolar amount of $\left[\mathrm{Bu}_{4} \mathrm{~N}\right]\left[\mathrm{ClO}_{4}\right]$ was added to a solution of $1 \cdot \mathrm{BAr}_{4}^{\prime}$ in $\mathrm{CD}_{2} \mathrm{Cl}_{2}$, the ${ }^{1} \mathrm{H}$ NMR signals of the $\left[\operatorname{Re}(\mathrm{CO})_{3}(\mathrm{Hdmpz})_{2}(2 \text {-ampy })\right]^{+}$complex did not change appreciably. Therefore, the coordination mode of the 2-ampy ligand in $\mathbf{1} \cdot \mathrm{BAr}^{\prime}{ }_{4}$ must be the same as in $\mathbf{1} \cdot \mathrm{ClO}_{4}$, in accord with the low interacting ability of the perchlorate anion.

In contrast, in the structure of $2 \cdot \mathrm{BAr}^{\prime}{ }_{4}$ (see Fig. 1(b)), the 3 -ampy ligand is bonded to the rhenium atom through the pyridine function. ${ }^{8}$ Compound $\mathbf{2} \cdot \mathrm{ClO}_{4}$ was prepared by anion exchange between $2 \cdot \mathrm{BAr}^{\prime}{ }_{4}$ and $\left[\mathrm{Bu}_{4} \mathrm{~N}\right]\left[\mathrm{ClO}_{4}\right]$, and its structure
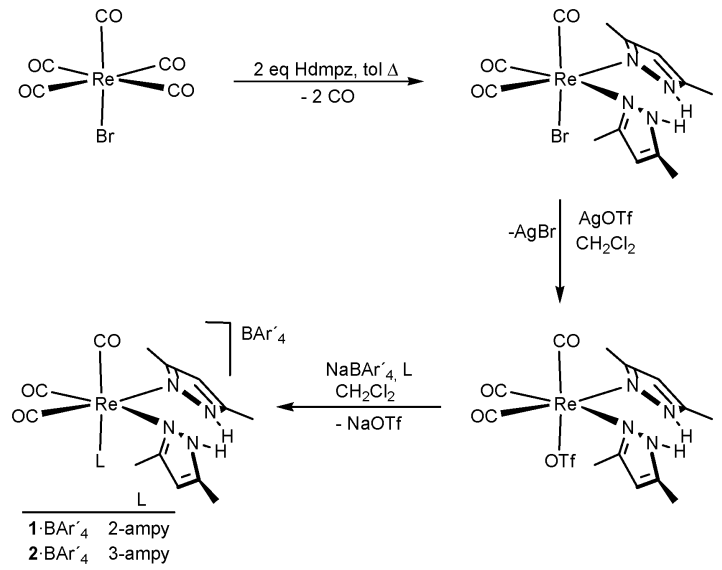

Scheme 1 Synthesis of compounds $\mathbf{1} \cdot \mathrm{BAr}^{\prime}{ }_{4}$ and $\mathbf{2} \cdot \mathrm{BAr}^{\prime}{ }_{4}$. 
a)

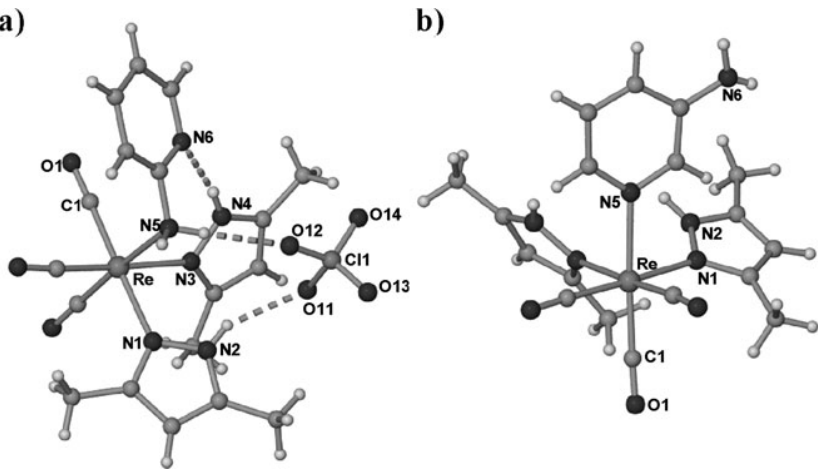

Fig. 1 (a) Molecular structure of the $\mathbf{1} \cdot \mathrm{ClO}_{4}$ adduct. (b) Molecular structure of $\left[\operatorname{Re}(\mathrm{CO})_{3}(\mathrm{Hdmpz})_{2}(3 \text {-ampy) }]^{+}\right.$in $\mathbf{2} \cdot \mathrm{BAr}^{\prime}{ }_{4}$.

was determined by X-ray diffraction (see ESI $\dagger$ ). The cationic complex $\left[\mathrm{Re}(\mathrm{CO})_{3}(\mathrm{Hdmpz})_{2}(3-\mathrm{ampy})\right]^{+}$in $\mathbf{2} \cdot \mathbf{C l O}_{4}$ is virtually identical to that found in $\mathbf{2} \cdot \mathrm{BAr}^{\prime}{ }_{4}$. The salt $\mathbf{2} \cdot \mathrm{ClO}_{4}$ features weak hydrogen bonding between the perchlorate anion and amino $\mathrm{N}-\mathrm{H}$ groups. The $\mathrm{NH}_{2}$ group is disordered between two positions related by rotation about the $\mathrm{Re}-\mathrm{N}$ (pyridine) bond. Both $\mathbf{1} \cdot \mathrm{BAr}^{\prime}{ }_{4}$ and $\mathbf{2} \cdot \mathrm{BAr}^{\prime}{ }_{4}$ were found to be stable in solution at room temperature during several days. Their behavior toward the tetrabutylammonium salts of several anions was investigated by IR and ${ }^{1} \mathrm{H}$ NMR. With chloride, bromide and nitrate, the IR bands of a $\mathrm{CH}_{2} \mathrm{Cl}_{2}$ solution of 1. $\mathrm{BAr}_{4}{ }_{4}$ shifted instantaneously some $10 \mathrm{~cm}^{-1}$ toward lower wavenumber values. In the case of chloride and bromide, the products were found to be the known neutral complexes $\left[\mathrm{ReCl}(\mathrm{CO})_{3}(\mathrm{Hdmpz})_{2}\right]^{2 a}$ and $\left[\operatorname{ReBr}(\mathrm{CO})_{3}(\mathrm{Hdmpz})_{2}\right],{ }^{9}$ indicating that the mentioned anions displaced the 2-ampy ligand. Unlike $\mathbf{1} \cdot \mathrm{BAr}_{4}^{\prime}, \mathbf{2} \cdot \mathrm{BAr}_{4}^{\prime}$ was found to be stable in the presence of tetrabutylammonium chloride, bromide and nitrate. The $1: 1$ adducts formed by the cationic complex $\mathbf{2}$ and the anions bromide (Fig. 2(a)) and nitrate (Fig. 2(b)) were crystallized from equimolar solutions of $\mathbf{2} \cdot \mathrm{BAr}^{\prime}{ }_{4}$ and the corresponding tetrabutylammonium salt in $\mathrm{CH}_{2} \mathrm{Cl}_{2}$ via slow diffusion of hexane at low temperature $\left(-20{ }^{\circ} \mathrm{C}\right)$. The structures of these adducts were determined by single-crystal X-ray diffraction, and the results are displayed in Fig. $2 .{ }^{10}$ In both adducts simultaneous hydrogen bonds between the anion and the $\mathrm{N}-\mathrm{H}$ groups of one pyrazole and the 3-ampy ligand, were found,

a)

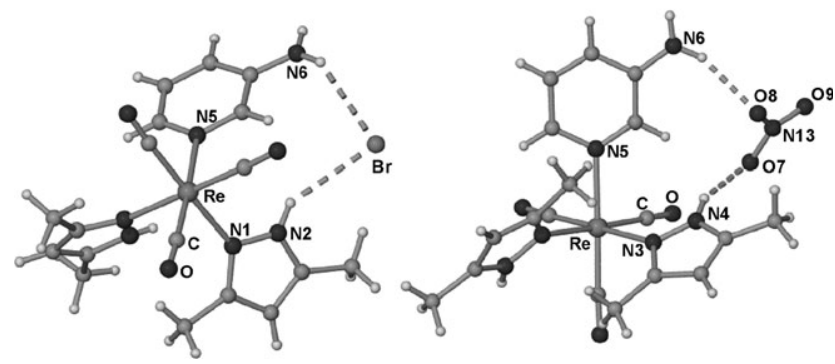

Fig. 2 Molecular structure of $\mathbf{2} \cdot \mathrm{Br}$ (a) [selected distances $(\AA)$ and angles $\left({ }^{\circ}\right)$ : $\mathrm{N} 2 \cdots \mathrm{Br} 3.534(8), \mathrm{N} 2-\mathrm{H} \cdots \mathrm{Br} 146.1 ; \mathrm{N} 6 \cdots \mathrm{Br} 3.440(8)$, $\mathrm{N} 6-\mathrm{H} \cdots \mathrm{Br}$ 154.9], and $\mathbf{2} \cdot \mathrm{NO}_{3}$ (b) [selected distances $(\AA)$ and angles

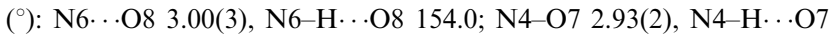
154.8] adducts. and are shown in dashed lines in Fig. 2 (more detailed views of these structures are given as ESI $\dagger$ ).

The difference in stability is attributed to the different coordination mode of the ampy ligand: the amine-ligated 2-ampy in $\mathbf{1} \cdot \mathrm{BAr}^{\prime}{ }_{4}$ is labile, whereas the pyridine-ligated 3-ampy in $\mathbf{2} \cdot \mathrm{BAr}^{\prime}{ }_{4}$ is stable. A higher stability of the $\sigma$-donor and $\pi$-acceptor pyridine compared with the only $\sigma$-donor amine is expected for a low oxidation organometallic fragment; besides, 2-ampy is sterically more hindered than 3-ampy, making its substitution by the anions more favored. As in tris(pyrazole) hosts, ${ }^{2}$ fluoride deprotonated $2 \cdot \mathrm{BAr}^{\prime}{ }_{4}$, as shown by a $21 \mathrm{~cm}^{-1}$ decrease in the $\nu_{\mathrm{CO}}$ values of the IR bands. Chloride, bromide and nitrate anions induced noticeable shifts in the ${ }^{1} \mathrm{H}$ NMR signals of the amine and pyrazole $\mathrm{N}-\mathrm{H}$ groups as well as in the ortho pyridine $\mathrm{C}-\mathrm{H}$ groups of $\mathbf{2} \cdot \mathrm{BAr}^{\prime}{ }_{4}$. The signals of the pyrazole $\mathrm{N}-\mathrm{H}$ groups underwent the larger anion-induced shifts and these were used for the calculation of binding constants. The exchange of the mentioned anions was found to be fast; therefore, binding constants were calculated from the variation of the chemical shifts of the signals of $\mathbf{2} \cdot \mathrm{BAr}^{\prime}{ }_{4}$ as a function of the amount of anion added. ${ }^{11}$ Titration curves are given as ESI. $\dagger$ A good 1: 1 fitting was found, and the calculated binding constants in acetonitrile were: $10^{4}$ (chloride), 142 (bromide) and 67 (nitrate). The selectivity (in this case, the large preference for chloride), which for fast anion exchange is simply given by the quotient of binding constants, is much higher than that found in tris(pyrazole) hosts, ${ }^{2}$ likely reflecting that only the smaller chloride can interact simultaneously with the hydrogen-bond donor groups of the three $\mathrm{N}$-donor ligands. These results indicate that mixed complexes with two different types of ligands functionalized with hydrogen-bond donor groups can be prepared as single products in good yield with the $\left\{\operatorname{Re}(\mathrm{CO})_{3}\right\}$ fragment, and that such complexes show promise as more selective anion hosts than the previously known complexes with a single type of functionalized ligand. Extension of these studies to other ligands is under way and will be published in due course.

We gratefully acknowledge funding from the Ministerio de Educación y Ciencia (grant CTQ2006-07036/BQU and Ramón y Cajal contract to L. R.) and the European Union (grant ERG-516505 to L. R.).

\section{Notes and references}

$\ddagger$ Synthesis of $\mathbf{1} \cdot \mathrm{BAr}_{4}{ }_{4}$ : $\left[\operatorname{ReBr}(\mathrm{CO})_{5}\right](0.100 \mathrm{~g}, 0.246 \mathrm{mmol})$ and $\mathrm{Hdmpz}$ $(0.047 \mathrm{~g}, 0.492 \mathrm{mmol})$ were refluxed in toluene $(20 \mathrm{~mL})$ for $30 \mathrm{~min}$. The solvent was evaporated under reduced pressure, the residue redissolved in $\mathrm{CH}_{2} \mathrm{Cl}_{2}(20 \mathrm{~mL})$, AgOTf $(0.063 \mathrm{~g}, 0.246 \mathrm{mmol})$ was added and the mixture was stirred in the dark for $1 \mathrm{~h}$. The resulting solution was filtered from the white solid through Celite, $\mathrm{NaBAr}_{4}{ }_{4}$ $(0.218 \mathrm{~g}, 0.246 \mathrm{mmol})$ and 2-ampy $(0.023 \mathrm{~g}, 0.246 \mathrm{mmol})$ were added, and the reaction mixture was allowed to stir at room temperature for $1 \mathrm{~h}$. The solution was concentrated under vacuum to a volume of $5 \mathrm{~mL}$ and addition of hexane $(20 \mathrm{~mL})$ caused the precipitation of a white solid, which was washed with hexane $(2 \times 15 \mathrm{~mL})$ and dried under vacuum. Compound $\mathbf{1} \cdot \mathrm{BAr}^{\prime}{ }_{4}$ was obtained as a white microcrystalline solid. Yield: $0.272 \mathrm{~g}, 78 \%$. IR $\left(\mathrm{CH}_{2} \mathrm{Cl}_{2}\right): 2037 \mathrm{vs}, 1934 \mathrm{~s}, 1917 \mathrm{~s}\left(\nu_{\mathrm{CO}}\right)$. ${ }^{1} \mathrm{H}$ NMR $\left(\mathrm{CD}_{2} \mathrm{Cl}_{2}\right): \delta 10.71[\mathrm{~s}, \mathrm{br}, 2 \mathrm{H}, \mathrm{NH}, \mathrm{Hdmpz}], 7.73\left[\mathrm{~m}, 9 \mathrm{H}, \mathrm{H}_{o}\right.$ and $\mathrm{CH}, \mathrm{BAr}^{\prime}{ }_{4}$ and 2-ampy], $7.57\left[\mathrm{~m}, 4 \mathrm{H}, \mathrm{H}_{p}, \mathrm{BAr}^{\prime}{ }_{4}\right], 7.44[\mathrm{~m}, 1 \mathrm{H}$, $\mathrm{CH}, 2$-ampy], 7.15 [m, 1H, CH, 2-ampy], 6.86 [m, 1H, $\mathrm{CH}, 2$-ampy], 6.12 [s, 2H, CH, Hdpmz], 5.32 [s, br, $\left.2 \mathrm{H}, \mathrm{NH}_{2}\right], 2.21\left[\mathrm{~s}, 6 \mathrm{H}, \mathrm{CH}_{3}\right.$, Hdmpz], 2.12 [s, 6H, $\left.\mathrm{CH}_{3}, \mathrm{Hdmpz}\right] .{ }^{13} \mathrm{C} \mathrm{NMR}\left(\mathrm{CD}_{2} \mathrm{Cl}_{2}\right): \delta 193.3[\mathrm{CO}]$ 
$191.6[2 \times \mathrm{CO}], 164.1\left[\mathrm{q}\left({ }^{1} J_{\mathrm{CB}}=50.0 \mathrm{~Hz}\right), \mathrm{C}_{i} \mathrm{BAr}^{\prime}{ }_{4}\right], 159.6[C 5(3)$, Hdmpz], 155.8 [2-ampy], 151.7 [C3(5), Hdmpz], 144.5, 141.8 [2-ampy], $134.7\left[\mathrm{C}_{o} \mathrm{BAr}^{\prime}{ }_{4}\right], 128.8\left[\mathrm{q}\left({ }^{2} J_{\mathrm{CF}}=32.1 \mathrm{~Hz}\right), \mathrm{C}_{m} \mathrm{BAr}_{4}^{\prime}{ }_{4}\right], 124.5\left[\mathrm{q}\left({ }^{1} J_{\mathrm{CF}}\right.\right.$ $\left.=272.9 \mathrm{~Hz}), \mathrm{CF}_{3}, \mathrm{BAr}_{4}^{\prime}\right], 117.5\left[\mathrm{C}_{p} \mathrm{BAr}_{4}^{\prime}\right.$ ], 116.5, 109.3 [2-ampy], $108.4[\mathrm{CH}, \mathrm{Hdmpz}], 14.6,10.8\left[\mathrm{CH}_{3}, \mathrm{Hdmpz}\right]$. Anal. Calc. for $\mathrm{C}_{50} \mathrm{H}_{37} \mathrm{BF}_{24} \mathrm{~N}_{5} \mathrm{O}_{3}$ Re: $\mathrm{C}$ 42.30, H 2.41, N 5.92. Found: C 41.97, H 2.52 , N $6.04 \%$.

$\S$ Synthesis of $2 \cdot \mathrm{BAr}_{4}^{\prime}$ : Prepared as described for $\mathbf{1} \cdot \mathrm{BAr}^{\prime}{ }_{4}$, from $\left[\operatorname{ReBr}(\mathrm{CO})_{5}\right](0.100 \mathrm{~g}, 0.246 \mathrm{mmol}), \mathrm{Hdmpz}(0.047 \mathrm{~g}, 0.492 \mathrm{mmol})$, $\mathrm{NaBAr}_{4}{ }_{4}(0.218 \mathrm{~g}, 0.246 \mathrm{mmol})$ and 3-ampy $(0.023 \mathrm{~g}, 0.246 \mathrm{mmol})$. Slow diffusion of hexane $(20 \mathrm{~mL})$ into a concentrated solution of 2. $\mathrm{BAr}_{4}{ }_{4}$ in $\mathrm{CH}_{2} \mathrm{Cl}_{2}$ afforded colorless crystals, one of which was used for the X-ray determination. Yield: $0.261 \mathrm{~g}, 75 \%$. IR $\left(\mathrm{CH}_{2} \mathrm{Cl}_{2}\right)$ : $2037 \mathrm{vs}, 1929 \mathrm{~s}\left(\nu_{\mathrm{CO}}\right) \cdot{ }^{1} \mathrm{H}$ NMR $\left(\mathrm{CD}_{2} \mathrm{Cl}_{2}\right): \delta 9.13[\mathrm{~s}$, br, $2 \mathrm{H}, \mathrm{NH}$, Hdmpz], 7.89 [m, 1H, CH, 3-ampy], $7.73\left[\mathrm{~m}, 9 \mathrm{H}, \mathrm{H}_{o}\right.$ and $\mathrm{CH}, \mathrm{BAr}^{\prime}{ }_{4}$ and 3-ampy], 7.57 [m, 4H, $\mathrm{H}_{p}, \mathrm{BAr}^{\prime}{ }_{4}$ ], 7.24 [m, 2H, CH, 3-ampy], 6.18 [s, 2H, CH, Hdpmz], 4.20 [s, br, 2H, N $H_{2}$ ], 2.30 [s, 6H, $\mathrm{CH}_{3}, \mathrm{Hdmpz}$, $2.23\left[\mathrm{~s}, 6 \mathrm{H}, \mathrm{CH}_{3}, \mathrm{Hdmpz}\right]{ }^{13} \mathrm{C} \mathrm{NMR}\left(\mathrm{CD}_{2} \mathrm{Cl}_{2}\right): \delta 196.0[\mathrm{CO}], 195.5$ $[2 \times \mathrm{CO}], 164.1\left[\mathrm{q}\left({ }^{1} J_{\mathrm{CB}}=49.9 \mathrm{~Hz}\right), \mathrm{C}_{i} \mathrm{BAr}^{\prime}{ }_{4}\right], 159.0,148.7[C 5$ and C3, Hdmpz], 147.4, 143.6, 142.1, 137.2 [2-ampy], 134.4 [C $\mathrm{C}_{o} \mathrm{BAr}_{4}{ }_{4}$ ], 131.2 [q $\left({ }^{2} J_{\mathrm{CF}}=31.3 \mathrm{~Hz}\right), \mathrm{C}_{m} \mathrm{BAr}^{\prime}{ }_{4}$ ], 130.1, 127.2 [3-ampy], 127.0 $\left[\mathrm{q} \quad\left({ }^{1} J_{\mathrm{CF}}=272.3 \mathrm{~Hz}\right), C_{3}, \mathrm{BAr}_{4}^{\prime}\right], 119.9 \quad\left[\mathrm{C}_{p} \mathrm{BAr}_{4}^{\prime}{ }_{4}\right], 111.3$ [CH, Hdmpz], 17.6, $13.3 \quad\left[\mathrm{CH}_{3}\right.$, Hdmpz]. Anal. Calc. for $\mathrm{C}_{50} \mathrm{H}_{37} \mathrm{BF}_{24} \mathrm{~N}_{5} \mathrm{O}_{3} \mathrm{Re}: \mathrm{C} 42.30, \mathrm{H} 2.41, \mathrm{~N}$ 5.92. Found: C 42.22, H $2.47, \mathrm{~N} 5.78 \%$.

1 C. R. Rice, Coord. Chem. Rev., 2006, 250, 3190; M. H. Filby and J. W. Steed, Coord. Chem. Rev., 2006, 250, 3200; P. D. Beer and E. J. Hayes, Coord. Chem. Rev., 2003, 240, 167; P. D. Beer and P. A. Gale, Angew. Chem., Int. Ed., 2001, 40, 486; M. G. Fisher, P. A. Gale, M. E. Light and S. J. Loeb, Chem. Commun., 2008, 5695; I. D. Vega, P. A. Gale, M. E. Light and S. J. Loeb, Chem. Commun., 2005, 4913; C. R. Bondy, P. A. Gale and S. J. Loeb, J. Am. Chem. Soc., 2004, 126, 5030; C. R. Bondy, P. A. Gale and S. J. Loeb, Chem. Commun., 2001, 729.

2 S. Nieto, J. Pérez, V. Riera, D. Miguel and C. Alvarez, Chem. Commun., 2005, 546; S. Nieto, J. Pérez, L. Riera, V. Riera and D. Miguel, Chem.-Eur. J., 2006, 12, 2244; S. Nieto, J. Pérez, L. Riera, V. Riera, D. Miguel, J. A. Golen and A. L. Rheingold, Inorg. Chem., 2007, 46, 3407.
3 J. Pérez, L. Riera, L. Ion, V. Riera, K. M. Anderson, J. W. Steed and D. Miguel, Dalton Trans., 2008, 878.

4 J. Pérez and L. Riera, Chem. Soc. Rev., 2008, 37, 2658.

5 K. J. Wallace, R. Daari, W. J. Belcher, L. O. Abouderbala, M. G. Boutelle and J. W. Steed, J. Organomet. Chem., 2003, 666, 63; S. J. Dickson, S. C. G. Biagini and J. W. Steed, Chem. Commun., 2007, 4955; S. J. Dickson, M. J. Paterson, C. E. Willans, K. M. Anderson and J. W. Steed, Chem.-Eur. J., 2008, 14, 7296.

6 Selected crystallographic data for 1. $\mathrm{ClO}_{4}: \mathrm{C}_{18} \mathrm{H}_{22} \mathrm{ClN}_{6} \mathrm{O}_{7} \mathrm{Re}$, $M=656.07$, monoclinic, $P 2_{1} / c, a=13.002(12), b=11.249(11)$, $c=17.183(16) \AA, \beta=106.685(17)^{\circ}, V=2407(4) \AA^{3}, Z=4,296$ $\mathrm{K} ; 10476$ reflections measured, 3458 independent $\left(R_{\mathrm{int}}=0.0413\right)$; $R_{1}=0.0264, w R_{2}=0.0561$ (all data).

7 M. M. Mashaly, Synth. React. Inorg. Met.-Org. Chem., 2004, 34, 115; C.-W. Su, C.-P. Wu, J.-D. Chen, L.-S. Liou and J.-C. Wang, Inorg. Chem. Commun., 2002, 5, 215; R. Bosque, F. Maseras, O. Eisenstein, B. P. Patel, W. Yao and R. H. Crabtree, Inorg. Chem., 1997, 36, 5505; R.-E. Shepherd and S. Zhang, Transition Met. Chem., 1994, 19, 146.

8 Selected crystallographic data for $2 \cdot \mathrm{BAr}_{4}^{\prime}: \mathrm{C}_{50} \mathrm{H}_{34} \mathrm{BF}_{24} \mathrm{~N}_{6} \mathrm{O}_{3} \mathrm{Re}$, $M=1419.84$, monoclinic, $P 2_{1} / n, a=14.512(3), b=25.848(5)$, $c=15.739(3) \AA, \beta=107.179(4)^{\circ}, V=5640.5(18) \AA^{3}, Z=4,293$ $\mathrm{K} ; 25132$ reflections measured, 8094 independent $\left(R_{\text {int }}=0.0417\right) ; R_{1}=0.0574, w R_{2}=0.1497$ (all data).

9 G. A. Ardizzoia, G. LaMonica, A. Maspero, M. Moret and N. Masciocchi, Eur. J. Inorg. Chem., 1998, 1503.

10 Selected crystallographic data for 2. $\mathrm{Br}$ : $\mathrm{C}_{18} \mathrm{H}_{23} \mathrm{BrN}_{6} \mathrm{O}_{4} \mathrm{Re}$, $M=653.53$, triclinic, $P \overline{1}, a=8.3635(3), b=8.9590(4)$, $c=16.4246(7) \AA, \alpha=104.396(4), \beta=90.268(3), \gamma=$ $107.713(4)^{\circ}, V=1131.21(9) \AA^{3}, Z=2, T=150 \mathrm{~K} ; 10083$ reflections measured, 4179 independent $\left(R_{\mathrm{int}}=0.0322\right) ; R_{1}=$ $0.0455, w R_{2}=0.1375$ (all data). $2 \cdot \mathrm{NO}_{3} \cdot 1 / 8 \mathrm{C}_{6} \mathrm{H}_{4} \cdot 1 / 8 \mathrm{CH}_{2} \mathrm{Cl}_{2}$ : $\mathrm{C}_{18.88} \mathrm{H}_{24} \mathrm{Cl}_{0.25} \mathrm{~N}_{7} \mathrm{O}_{6} \mathrm{Re}, M=640.01$, monoclinic, $P 2_{1} / c, a=$ 17.1425(2), $b=18.6344(3), c=19.2945(3) \AA, \beta=108.678(2)^{\circ}$, $V=5838.83(15), \AA^{3}, Z=8, T=150 \mathrm{~K} ; 29294$ reflections measured, 11272 independent $\left(R_{\mathrm{int}}=0.0331\right) ; R_{1}=0.0773$, $w R_{2}=0.2221$ (all data).

11 M. J. Hynes, J. Chem. Soc., Dalton Trans., 1993, 311. 